\title{
Pembelajaran dan Pelatihan Teknologi Informasi dan Komunikasi Dasar bagi Siswa Sekolah Dasar
}

\author{
Fuad Indra Kusuma, Mokhamad Ilham Firdaus*, Nurul Afifah \\ Universitas Negeri Malang, Jl. Semarang No. 5 Malang, Jawa Timur, Indonesia \\ *Penulis korespondensi, Surel: mokhamad.ilham.1805166@students.um.ac.id
}

Paper received: 2-11-2021; revised: 17-11-2021; accepted: 23-11-2021

\begin{abstract}
Over time, technology has had a major impact on the education and learning process. Technology can support all needs in the education and learning process. Therefore, it is necessary to provide basic knowledge of Information and Communication Technology (ICT) to teach the importance of strong foundations to instill understanding in the younger generation. ICT learning is one of the work programs of the Real Work Lecture (KKN) at the State University of Malang in the Donomulyo Village group, which was held on Thursday, December 9, 2021, at SDN 3 Donomulyo at the 3rd grade level. ICT learning was carried out with 3 methods, namely conventional methods, question and answer method and demonstration method. As a result, the students were enthusiastic in accepting this ICT learning. It is also hoped that the local government will contribute to assisting in the needs of this ICT learning.
\end{abstract}

Keywords: learning; training; ICT; Elementary School

\begin{abstract}
Abstrak
Seiring berjalannya waktu, teknologi telah memberikan dampak yang besar terhadap proses Pendidikan dan pembelajaran. Teknologi dapat mendukung segala kebutuhan dalam proses pendidikan dan pembelajaran. Oleh sebab itu, perlu diberikan ilmu dasar Teknologi Informasi dan Komunikasi (TIK) untuk mengajarkan pentingnya dasar-dasar yang kuat untuk menanamkan pemahaman kepada generasi muda. Pembelajaran TIK menjadi salah satu program kerja dari kegiatan Kuliah Kerja Nyata (KKN) Membangun Desa Universitas Negeri Malang kelompok Desa Donomulyo yang dilaksanakan pada Kamis, 9 Desember 2021 di SDN 3 Donomulyo pada tingkat kelas 3. Pembelajaran TIK dilakukan dengan 3 metode, yaitu metode konvensional, metode tanya jawab dan metode demonstrasi. Hasilnya para siswa siswi antusias dalam menerima pembelajaran TIK ini. Diharapkan juga pemerintah setempat turut andil membantu dalam membantu dalam kebutuhan pembelajaran TIK ini.
\end{abstract}

Kata kunci: pembelajaran; pelatihan; TIK; SD

\section{Pendahuluan}

Seiring berjalannya waktu, teknologi telah memberikan dampak yang besar terhadap proses pendidikan dan pembelajaran, mulai dari Sekolah Dasar hingga ke jenjang yang lebih tinggi. Terlebih di masa pandemi Covid-19 yang menuntut kegiatan belajar dilaksanakan secara daring (online).

Teknologi dapat mendukung segala kebutuhan dalam proses pendidikan dan pembelajaran. Dengan berkembangnya zaman teknologi, saat ini sudah banyak teknologi yang dapat membantu pelaksanaan pembelajaran. Teknologi berperan sangat penting dalam peningkatan kualitas pendidikan sawah. Selain itu, peran teknologi dapat meningkatkan efektifitas dan efisiensi proses pendidikan dan pembelajaran dalam membantu pencapaian tujuan Pendidikan (Salsabila, Sari, Lathif, Lestari, \& Ayuning, 2020). 
Oleh sebab itu, perlu diberikan ilmu dasar Teknologi Informasi dan Komunikasi (TIK) untuk mengajarkan pentingnya dasar-dasar yang kuat untuk menanamkan pemahaman kepada generasi muda tentang etika dan moral dalam memanfaatkan Teknologi Informasi dan Komunikasi.

Pembelajaran TIK menjadi salah satu program kerja dari kegiatan Kuliah Kerja Nyata (KKN) Membangun Desa Universitas Negeri Malang kelompok Desa Donomulyo, Kecamatan Donomulyo Kabupaten Malang. Pembelajaran ilmu dasar TIK ini dilaksanakan pada siswasiswi kelas tiga salah satu sekolah dasar yaitu di SDN 3 Donomulyo pada hari Kamis, 09 Desember 2021. Sekolah ini menjadi tujuan pelaksanaan pembelajaran TIK sebagai upaya pengenalan dan pembelajaran ilmu TIK sekolah dasar.

Mengingat pentingnya peran TIK dalam berbagai aspek kehidupan era digital sekarang, maka dapat disimpulkan tujuan pembelajaran TIK adalah sebagai upaya membekali generasi muda bangsa agar mampu mengembangkan diri dengan cara mengakses, mengolah, menyeleksi, mengkolaborasi dan mengkomunikasikan informasi secara maksimal di segala bidang baik ekonomi, sosial, budaya dan keagamaan.

\section{Metode}

Metode merupakan suatu cara yang dapat digunakan untuk memecahkan masalah guna mencapai tujuan yang diinginkan (Sugiyono, 2008). Dari pengertian tersebut, metode yang dilakukan dapat diartikan sebagai sebuah kegiatan yang dapat dilaksanakan agar tujuan dapat mencapai tujuan yang diharapkan.

\subsection{Tahapan}

Penjabaran alur pada pelaksanaan program kerja pembelajaran TIK bagi siswa SDN 3 Donomulyo dapat terlihat sebagai berikut:

1. Meminta izin kepada pihak desa Donomulyo dan kepala desa Donomulyo untuk pelaksanaan program kerja Pembelajaran TIK bagi siswa Sekolah Dasar Donomulyo.Meminta izin kepada pihak sekolah melalui kepala sekolah SDN 3 Donomulyo untuk pelaksanaan program kerja Pembelajaran TIK bagi siswa kelas 3 SDN 3 Donomulyo.

3. Pencarian sumber buku yang relevan untuk dijadikan pustaka bahan ajar TIK dasar bagi siswa Sekolah Dasar kelas 3.

4. Penyampaian materi TIK dasar menggunakan Powerpoint dengan menerapkan metode konvensional atau ceramah dan juga metode tanya jawab.

5. Pelatihan dengan praktik langsung belajar mengetik pada Software Microsoft Word dengan menerapkan metode demonstrasi.

6. Setelah semua tahapan program kerja selesai, langkah selanjutnya adalah membuat laporan dan artikel.

Untuk mencapai tujuan yang diharapkan, dari alur program pembelajaran TIK di SDN 3 Donomulyo dilaksanakan dengan menggunakan metode pembelajaran ceramah, tanya jawab, dan demonstrasi. 
1. Metode Konvensional atau Ceramah

Metode Ceramah digunakan karena merupakan salah satu metode pembelajaran yang paling praktis dan tidak membutuhkan banyak alat bantu (Dewi, 2018).

2. Metode Tanya Jawab

Metode Tanya Jawab adalah metode mengajar yang memungkinkan terjadinya komunikasi langsung yang bersifat dua arah, sebab pada saat yang sama terjadi dialog antara pemateri dan siswa (Sitohang, 2017).

\section{Metode Demonstrasi}

Metode demonstrasi adalah metode mengajar yang membantu para siswa untuk memperoleh jawaban dengan mengamati dan melakukan suatu proses atau peristiwa tertentu (Nahdi, Yonanda, \& Agustin, 2018).

\subsection{Lokasi}

Lokasi pelaksanaan program kerja pembelajaran TIK untuk Sekolah Dasar berada di SDN 3 Donomulyo yang beralamat di JL. Jakarta No. 71, RT. 02, RW. 01, Dusun Bandung, Desa Donomulyo, Kecamatan Donomulyo, Kabupaten Malang, Provinsi Jawa Timur.

\subsection{Durasi Waktu}

Durasi pelaksanaan program kerja Pembelajaran TIK dilaksanakan selama 1 hari pada hari Kamis, 9 Desember 2021 dimulai dari pukul 07.00 pagi hingga 09.30 pagi atau selama 150 menit.

Tabel 1. Rundown Program Kerja Pembelajaran TIK

\begin{tabular}{ccc}
\hline Kegiatan & Waktu & Keterangan \\
\hline Persiapan Kegiatan & $07.00-07.15$ & Persiapan peralatan \\
Pembukaan & $07.15-07.15$ & Salam dan perkenalan \\
Penyampaian Materi I & $07.15-07.35$ & Penjelasan TIK dasar \\
Penyampaian Materi II & $07.35-07.45$ & Penjelasan Microsoft Office \\
Ice Break & $07.45-07.50$ & \\
Pembagian Kelompok & $07.50-07.55$ & Siswa dibagi menjadi 4 kelompok \\
Istirahat & $07.55-08.15$ & \\
Penyampaian Materi III & $08.15-08.20$ & Penjelasan Microsoft Word \\
Praktik & $08.20-09.20$ & Praktik mengetik \\
Penutupan & $09.20-09.30$ & Penutupan dan dokumentasi \\
\hline
\end{tabular}

\section{Hasil dan Pembahasan}

\subsection{Metode Konvensional}

Dilaksanakan selama kurang lebih 30 menit guna menyampaikan materi ilmu dasar TIK sebagai pengantar kepada siswa sebelum melaksanakan praktik mengetik pada software Microsoft Word. Materi yang disampaikan antara lain mengenai pengertian TIK, contoh alatalat TIK, pengertian komputer, bagian-bagian komputer, pengertian software, pengertian 
hardware, dan pengenalan Microsoft Office yang disampaikan di depan 12 siswa kelas 3 SDN 3 Donomulyo. Hasilnya para siswa terlihat cukup antusias dalam menerima materi yang disampaikan.
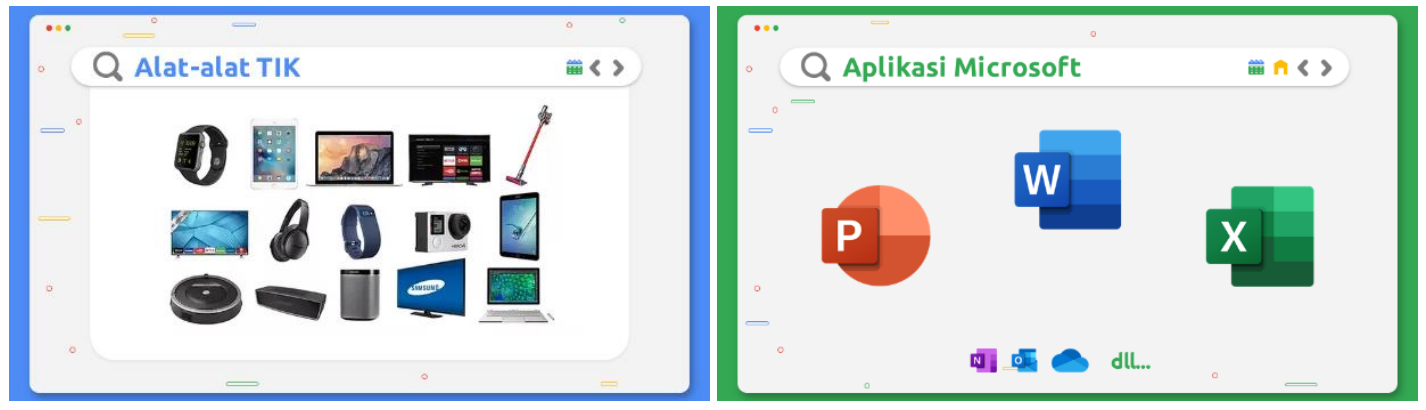

\section{Gambar 1. Materi Pembelajaran TIK}

\subsection{Metode Tanya Jawab}

Diselingi dengan metode tanya jawab, metode tanya jawab digunakan beberapa kali selama penyampaian materi untuk lebih menarik dan melatih siswa lebih berani dan berpikir kritis dalam memahami materi. Metode tanya jawab ini dilakukan dengan membuka pertanyaan atau quiz kepada siswa dan memberikan reward berupa makanan ringan kepada siswa yang sudah berani menjawab pertanyaan yang diberikan oleh pemateri. Metode ini juga digunakan sebagai indikasi bahwa materi yang telah disampaikan sudah diterima dan dipahami oleh setiap siswa. Selama proses tanya jawab siswa cukup aktif dalam bertanya dan menjawab pertanyaan pemateri.

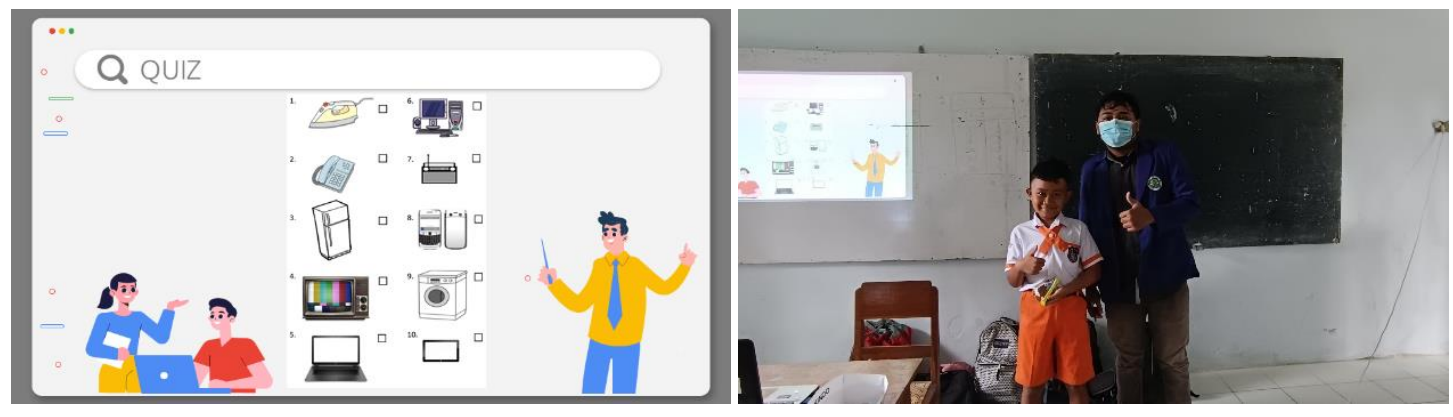

Gambar 2. Quiz dan Pemberian Reward

\subsection{Metode Demonstrasi}

Dilakukan pada 12 siswa yang dibagi menjadi empat kelompok, dengan masing-masing kelompok beranggotakan 3 siswa dan terdapat satu buah laptop, selama 60 menit untuk mengimplementasikan materi TIK yang telah diberikan dan melatih siswa mengetik dengan 
cara diberi sebuah teks latihan. Setiap siswa diberikan kesempatan untuk menggunakan dan mengetik seperti contoh teks yang diberikan yang berguna dalam memberikan pengalaman pada setiap siswa sehingga bisa memberikan tambahan ilmu secara langsung dari permasalah yang dialami selama praktik mengetik.

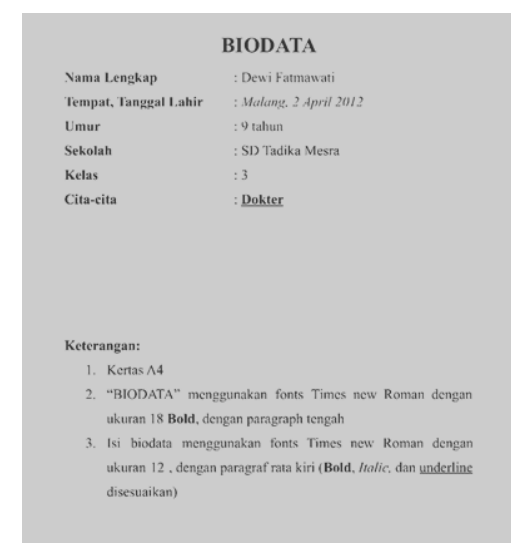

\section{Gambar 3. Lembar Latihan Mengetik Microsoft Word}

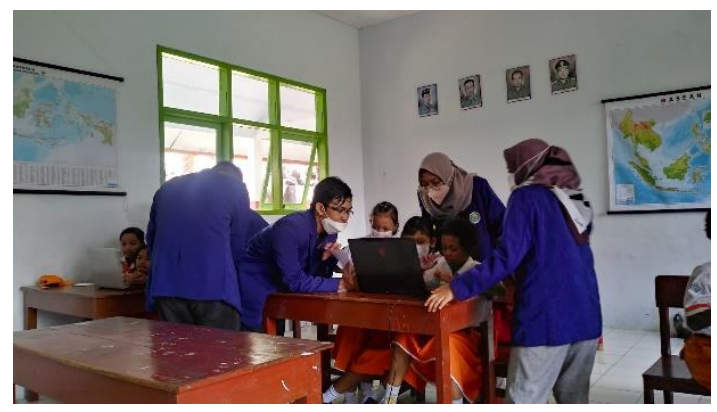

Gambar 4. Pendampingan Praktik Mengetik di Microsoft Word

\section{Simpulan}

Pembelajaran dan pelatihan TIK dapat meningkatkan kemampuan berpikir, bersikap, dan bertindak dalam mengikuti perkembangan. Program kerja ini mendukung siswa SDN 3 Donomulyo dalam pengembangan diri di bidang TIK. Program kerja ini memberikan pengalaman dan keterampilan kepada siswa dalam memanfaatkan teknologi yang ada dengan baik. Selain itu, dengan adanya program kerja ini mampu memberikan keadaan kelas lebih menarik atau menyenangkan bagi siswa dan dapat memotivasi siswa agar lebih giat belajar menyerap ilmu yang diberikan.

\section{Ucapan Terima Kasih (Opsional)}

Penulis menyampaikan terima kasih kepada pihak-pihak yang terlibat: Kepala Sekolah SDN 3 Donomulyo, para guru dan siswa SDN 3 Donomulyo, Kepala desa Donomulyo beserta jajaranya, dan warga Desa Donomulyo yang telah memberi dukungan moral dan bantuan 
terhadap program pengabdian masyarakat ini, yaitu program kerja pembelajaran TIK bagi siswa SDN 3 Donomulyo.

\section{Daftar Rujukan}

Dewi, E. R. (2018). Metode Pembelajaran Modern dan Konvensional Pada Sekolah Menengah Atas. Jurnal Ilmu $\begin{array}{llll}\text { Pendidikan, Keguruan, dan } & \text { Pembelajaran, }\end{array}$ https://doi.org/https://doi.org/10.26858/pembelajar.v2i1.5442

Nahdi, D. S., Yonanda, D. A., \& Agustin, N. F. (2018). Upaya Meningkatkan Pemahaman Konsep Siswa Melalui Penerapan Metode Demonstrasi Pada Mata Pelajaran IPA. Jurnal Cakrawala Pendas, 4(2).

Salsabila, U. H., Sari, L. I., Lathif, K. H., Lestari, A. P., \& Ayuning, A. (2020). Peran Teknologi Dalam Pembelajaran Di Masa Pandemi Covid-19. JURNAL AL-MUTHARAHAH: JURNAL PENELITIAN DAN KAJIAN SOSIAL KEAGAMAAN, 17(2). https://doi.org/https://doi.org/10.46781/al-mutharahah.v17i2.138

Sitohang, J. (2017). Penerapan Metode Tanya Jawab Untuk Meningkatkan Hasil Belajar Ipa Pada Siswa Sekolah Dasar. Suara Guru: Jurnal Pendidikan Sosial, Sains dan Humaniora (SG-JPSSH), 3(4), 681-688. https://doi.org/http://dx.doi.org/10.24014/suara\%20guru.v3i4.4851

Sugiyono. (2008). Metode Penelitian Pendidikan (Pendekatan Kuantitatif, Kualitatif dan R\&D). 